\title{
Characterization of a polyubiquitin gene in T. thermophila and of ubiquitin gene expression during sexual reproduction and under stress conditions
}

- P. Guerreiro,

- $\quad$ C. Rodrigues-Pousada,$\nabla$

- Laboratório de Genética Molecular, Instituto Gulbenkian de Ciência, Apartado 14, 2781 Oeiras, Portugal

- Corresponding author. Fax. +351 14435625

\section{Abstract}

A 5-unit polyubiquitin gene, TTU3, was isolated from a T. thermophila genomic library and sequenced. This gene presents an extra triplet coding for Phe, a AGAGA motif and a putative HSE element in its 5 '-non-coding region. The ubiquitin gene expression in this ciliate was investigated by Northern blot hybridization in conjugating cells or cells under stress conditions. Exponentially growing cells express two ubiquitin mRNAs of 0.75 and $1.8 \mathrm{~kb}$ and a new species of $1.4 \mathrm{~kb}$ is induced under hyperthermic stress. During sexual reproduction of the cells (conjugation) the 1.8-kb mRNA is still transcribed whereas the steady-state population of the 0.75 mRNA transcripts is strongly diminished. Southern blot analysis suggests that ubiquitin in T. thermophila constitutes a large family of about ten members.

\section{Keywords}

- Ubiquitin mRNAs;

- Genomic organization;

- Tetrahymena;

- Ciliate;

- Conjugation;

- Hyperthermic stress 


\section{Abbreviations}

- bp, base pair(s);

- HSE, heat shock element;

- kb, kilobase(s) or 1000 bp;

- SDS, sodium dodecyl sulfate;

- $\mathrm{SSC}, 150 \mathrm{mM} \mathrm{NaCl} / 15 \mathrm{mM}$ sodium citrate $\mathrm{pH}$ 7.0;

- T., Tetrahymena;

- Ub, ubiquitin(s);

- Ub, gene encoding Ub;

- $\quad:$, novel junction (fusion or insertion)

Gene, Volume 182, Issues 1-2, 5 December 1996, Pages 183-188

http://dx.doi.org/10.1016/S0378-1119(96)00551-3

\section{Article history}

Received 7 February 1996

Revised 6 June 1996

Accepted 2 July 1996

Available online 22 March 1999 